\title{
GRAMMAR LEARNING STRATEGIES AND LANGUAGE ATTAINMENT: SEEKING A RELATIONSHIP
}

\author{
Mirostaw Pawlak \\ pawlakmi@amu.edu.pl \\ Adam Mickiewicz University, Kalisz
}

\begin{abstract}
Despite major advances in research on language learning strategies, there are still areas that have received only scant attention, and one of them is undoubtedly learning grammar. The paper contributes to the paucity of empirical investigations in this domain by presenting the findings of a study which sought to investigate the relationship between the use of grammar learning strategies (GLS) reported by 142 English Department students and target language attainment, operationalized as their performance in a practical grammar course and the end-of-the-year examination. Information about GLS use was obtained by means of a tool that was designed on the basis of a theoretical scheme proposed by Oxford, Rang Lee and Park (2007) in which GLS are divided into three categories depending on whether they represent implicit learning with focus on form, explicit inductive learning and explicit deductive learning. The analysis failed to find a strong positive relationship between the use of GLS and achievement, irrespective of the level of the BA program, or statistically significant differences in this respect between lower-level and higher-level participants. The highest, albeit very weak, correlation was identified between the use of GLS associated with explicit deductive learning and grammar course grades, which testifies to the traditional nature of instruction the subjects receive. The findings serve as a basis for putting forward a handful of recommendations for learning, teaching and testing grammar as well as directions for future studies into grammar learning strategies.
\end{abstract}

Key words: grammar learning strategies, language attainment, language proficiency, instructional mode

\section{Introduction}

Ever since the publication of the seminal paper by Rubin (1975) in which she attempted to list the techniques and approaches employed by successful language learners, huge strides have been made in language learning strategy theory and research. Although there are still vigorous debates concerning the definition, nature and characteristics of the actions and thoughts that learners draw upon in their efforts to master a foreign language, several major classifications of strategic devices have been proposed, major factors affecting their use have been identified, their positive impact on language development has been ascertained, and the value of strategy training programs has been verified (cf. Chamot 2004; Anderson 2005; Dörnyei 2005; Macaro 2006; Cohen and 
Macaro 2007; Griffiths 2008a). Despite such undeniable accomplishments, there are some key areas in which language learning strategy research remains in its infancy and specialists are only beginning to make inroads, with grammar being a prime case in point. Such a situation is both surprising and disconcerting since the ability to use points of grammar in an accurate, meaningful and appropriate way (Larsen-Freeman 2003) is a high priority for many language learners and, therefore, showing them how to attain this goal effectively is the responsibility of their teachers. In order to successfully confront this challenge, however, practitioners should be aided by second language acquisition theorists and researchers, and, in fact, the pressing need for pursuing this line of enquiry has been expressed in several recent publications. Anderson, for example, writes that "What is greatly lacking in the research are studies that specifically target the identification of learning strategies that L2 learners use to learn grammar and to understand the elements of grammar" (2005: 766), while Oxford, Rang Lee and Park point out that "Collaborative, interdisciplinary research on grammar strategies will benefit learners everywhere, as well as facilitating the work of L2 teachers and helping us all understand better how people learn another language" (2007: 137).

As the present author has argued elsewhere (Pawlak 2008a, 2009a), the most urgent goal for empirical investigations of this kind is the identification, description and classification of grammar learning strategies (GLS) with an eye to providing a basis for further studies which would establish their value, investigate mediating variables and determine the contributions of strategies-based instruction. Nevertheless, it also seems warranted to examine these issues with the help of the research tools currently at our disposal, since, imperfect as they might be, they can furnish invaluable insights which can facilitate the development of a comprehensive GLS taxonomy as well as valid and reliable data collection instruments. This was the rationale behind the study reported in the present paper which sought to investigate the relationship between the use of grammar learning strategies reported by advanced learners of English and language attainment, operationalized as their performance in a practical grammar course and the end-of-the-year examination. In the first part, key issues concerning grammar learning strategies will be discussed and the findings of research targeting the relationship between strategy use and proficiency will be overviewed. This will be followed by the description of the design of the research project, the data collection instruments and the analytical measures, and the presentation, discussion and interpretation of the results. The paper will close with a handful of recommendations for learning, teaching and testing grammar as well as directions for future studies into grammar learning strategies.

\section{Grammar learning strategies in theory and research}

Basing on a more general definition of language learning strategies offered by Oxford (1990), Oxford, Rang Lee and Park (2007: 117) describe grammar learning strategies as "(...) actions and thoughts that learners consciously employ to make language learning and/or language use easier, more effective, more efficient, and more enjoyable" (2007: 117). Similarly to all other types of strategic behaviors, GLS possess distinctive characteristics which Griffiths (2008a) summarizes as follows: (1) they are what learners do, which indicates an active approach, (2) their application is at least partly conscious, 
(3) they are optional means learners choose, (4) their use entails goal-oriented, purposeful activity, (5) they are applied to regulate and control the process of learning, and (6) their use is intended to facilitate the process of learning. Thus far, little attempt has been made to provide a theoretical framework of the activities learners draw upon in learning grammar or to propose a comprehensive classification of these strategic devices, with researchers primarily relying on more general models and classifications. One notable exception in this respect is the descriptive scheme put forward by Oxford, Rang Lee and Park (2007) which can serve as a basis for developing a tentative taxonomy of GLS as well as a data collection tool, one which can be profitably exploited in the preliminary stages of research in this area and has in fact been utilized in the present study. Drawing upon recent advances in research on form-focused instruction (e.g. Doughty 2003; DeKeyser 2003; Ellis 2006), they make a distinction between three categories of grammar learning strategies which can be associated with three main instructional approaches to teaching grammatical structures. These are as follows: (1) GLS reflective of implicit L2 learning that includes a focus on form (i.e. attending to form in the course of meaning and message conveyance), such as noticing grammatical structures that cause problems with meaning or communication, paying attention to how more proficient people say things and imitating, noticing correction of erroneous utterances, etc., (2) GLS facilitating explicit inductive L2 learning (i.e. discovering patterns and rules on the basis of the input data), such as participating in rule-discovery discussions in class, creating and testing hypotheses about how target structures operate, checking with more proficient peers whether a given rule interpretation is correct, etc., and (3) GLS applicable to explicit deductive learning (i.e. employing the rules presented by the teacher in different types of activities), such as previewing the lesson to identify the key grammatical structures to be covered, paying attention to rules provided by the teacher or the coursebook, memorizing how structures change their form, etc. While the classification is without a doubt a useful point of departure for investigating grammar learning strategies, it is not free from limitations which have to be borne in mind when discussing and interpreting the findings of studies in which it has been utilized. Among other things, by categorizing GLS according to instructional modes, it adopts a teachercentered rather than a learner-oriented perspective, it ignores the existing taxonomies of strategies, emphasizes cognitive devices at the expense of other strategy types, places a premium on noticing, understanding and remembering grammar structures without giving ample justice to the ways in which points of grammar are practiced, and includes quite a few techniques that are reflective of cutting-edge approaches to grammar instruction that may be alien to teachers and learners (cf. Pawlak 2008a, 2009a).

As made plain in the introduction to this paper, research into GLS is still in its budding stage, with specialists having yet to identify, describe and account for all the various strategic behaviors that learners fall back upon when studying target language grammar, not to mention appraise their effectiveness, determine the effects of training or describe the factors impacting their use. The scant information about techniques applied in learning grammatical structures comes from studies which have sought the explore the entire repertoire of strategic devices used by specific groups of participants as well as such, typically more recent ones, which have been specifically conducted to examine the application of GLS. The former strand of research is represented by the good language learner studies of the 1970s and 1980s (e.g. Rubin 1975; Stern 1975; Naiman et al. 
1978/1996) which demonstrated that success in mastering a foreign language hinges among other things upon the capacity to focus both on meaning and form as well as the empirical investigations which provided a basis for the two main classifications of strategic devices proposed by O'Malley and Chamot (1990) and Oxford (1990). In the Polish context, a landmark research project was carried out by Droździał-Szelest (1997), who used surveys to identify the strategies employed by high school students and found that, in the case of grammar, they were mainly cognitive, unoriginal, and reflective of predominant, traditional instructional practices. As regards empirical investigations focused exclusively on GLS, the first studies of this kind attempted to identify the strategies learners use to assign gender to nouns in the mother tongue or additional languages (e.g. Karmiloff-Smith 1977; Stevens 1984; Oliphant 1997), but, even though such evidence is illuminating, most language strategy experts have elected to pay little heed to it. Somewhat more in line with mainstream strategy research are the studies conducted by Fortune (1992), who investigated learners' preferences concerning selfstudy grammar practice activities, as well as Bade (2008), who found that ESL students are willing to focus on accuracy, invite error correction and use a range of strategies in learning grammar. In recent years, however, studies of GLS have been a particularly robust line of enquiry in Poland, with researchers exploring their application by learners representing different ages and educational levels. Mystkowska-Wiertelak (2008a, 2008b), for example, found that secondary school learners most frequently use metacognitive strategies while English Department students predominantly rely on the cognitive strategies of analyzing and resourcing but their overall repertoire of GLS is extremely limited. The latter finding has been corroborated by Pawlak (2008a) who showed that although advanced learners are cognizant of the need to employ a variety of GLS, they manifest a propensity to use rather traditional cognitive strategies such as formal practice. In another study with a similar group of subjects, which was the first part of the research project reported in this paper, Pawlak (2009a) utilized a data collection instrument designed on the basis of the taxonomy proposed by Oxford, Rang Lee and Park (2007). He found that the reported high use of GLS related to implicit learning with focus on form may not be reflective of reality in which much more traditional strategies are preferred. There is also a handful of studies which sought a relationship between the use of GLS and proficiency, but their results will be outlined in the subsequent section which overviews more general strategy research in this area.

\section{Interfaces between language learning strategy use and proficiency}

In the words of Anderson (2005: 762), "The research conducted to date has been consistent in linking levels of L2 proficiency to strategy use. Proficient L2 learners have been found to have a wider repertoire of strategies and draw on them to accomplish L2 tasks". Such claims have also been advanced by other researchers, with Oxford (2001) arguing that strategy use may account for up to 61 percent of the variability in English proficiency scores and Chamot (2004: 18) stating that "Differences between more and less proficient language learners have been found in the number and range of strategies used, in how the strategies are applied to the task, and in the appropriateness of the strategies for the task". Although such assumptions find considerable support in the 
findings of numerous studies, some specialists are convinced that caution should be exercised in arguing that there exist cause-and-effect relationships between learning strategy use and TL achievement (Macaro 2001; Grenfell and Macaro 2007; Ellis 2008, etc.). This is because there is also evidence suggesting that the influence of strategy use on proficiency is far from straightforward, establishing a positive link between these factors is not tantamount to determining the direction of causality, diverse measures of strategy use and achievement have been employed, and the contribution of strategic devices may vary as a function of individual characteristics, the task at hand, the ways in which they are clustered in strategy chains, or the aspect of L2 proficiency (Ehrman, Leaver and Oxford 2003; Takeuchi, Griffiths and Coyle 2007; Ellis 2008). The present section provides a brief overview of the findings of studies seeking to relate learning strategy use to achievement, including the few which have squarely focused on identifying such a relationship in the case of GLS.

Obviously, earliest evidence for the connection between the application of strategies and success in language learning comes from good language learner studies, already referred to in the previous section with respect to GLS, which either confined themselves to identifying the approaches adopted by successful learners or compared them with less successful individuals. According to Ellis $(1994,2008)$, the findings reported by such researchers as Rubin (1975), Stern (1975) or Naiman et al. (1978/1996) or Reiss (1985) make it possible to identify five main aspects of successful learning, namely (1) a concern for language form, (2) a concern for communication, (3) an active task approach, (4) awareness of the learning process, and (5) a capacity to use strategies flexibly in accordance with the requirements of a specific task. A positive relationship between strategy use and achievement has also been found in numerous later studies which were mostly correlational in nature. For example, Philips (1991) reported a strong connection between the frequency with which his subjects used strategies determined by means of the Strategy Inventory for Language Learning (SILL) and proficiency established on the basis of TOEFL scores, a finding which was subsequently corroborated by Takeuchi (1993), Park (1994), and Dreyer and Oxford (1996). Many other studies have yielded similar results, with Green and Oxford (1995) reporting that all strategy types contribute to success, Park (1997) claiming that cognitive and social strategies are most predictive of attainment, Bremner (1999) reaching similar conclusions but adding compensation behaviors to the list, Sheorey (1999) stressing the importance of functional practice, and Griffiths (2008a) singling out metacognitive devices as well as such that expand vocabulary, improve the knowledge of grammar, involve the use of resources and integrate skills. Other researchers have also found a positive link between the frequency of strategy use and self-rated proficiency (Osanai 2000; Wharton 2000). When it comes to GLS, Mystkowska-Wiertelak (2008a, 2008b) reported that greater use of such devices is related to superior outcomes in learning grammar for secondary school learners and English Department students, although the failure to employ inferential statistics dictates that these findings should be interpreted with circumspection.

At the same time, however, there are studies which have failed to provide unequivocal evidence for the existence of a relationship between the frequency of learning strategy use and achievement or at least identified some mediating variables which may affect its linearity and strength. In an early research project, for example, 
Bialystok (1981) investigated the impact of four strategies on L2 proficiency and reported that inferencing was not in any way related to achievement whereas the importance of functional practice, formal practice and monitoring depended upon the level the participants represented. Even less promising are the results of a study conducted by Politzer and McGroarty (1985) who set out to relate the use of strategies employed by learners inside the classroom, during individual study and in social interaction. They found only a weak correlation between the application of strategic devices and a test of communicative ability, and no impact of individual strategies on attainment, although clusters of particular behaviors did correlate with gains on some tests. In more recent studies, Mullins (1992) reported few significant relationships between strategy use measured by means of SILL and the participants' attainment operationalized as entrance examination, placement test and GPA scores, Oxford and Ehrman (1995) found that only some cognitive strategies were positively correlated with end-of-semester grades while Nisbet, Tindall and Arroyo (2005) showed that only metacognitive strategies were related to TOEFL scores, accounting for just $4 \%$ of the variance in this respect. The complexity of the relationship between strategy use and attainment is also evident in the results of a study carried out by Magogwe and Oliver (2007) who reported that proficiency can be linked to the preference for particular strategy types at the primary but not secondary or tertiary level. The relationship between GLS use by Turkish students and achievement was examined in a study conducted by Tilfarlioğlu (2005) who reported no differences in the frequency with which successful and unsuccessful learners drew upon these devices.

In the light of such mixed and inconclusive empirical evidence, it would appear that we should be circumspect in making claims about the existence of a positive relationship between strategy use and TL achievement, and that the confidence manifested in this respect by some specialists might not be fully warranted. Much more reasonable and reflective of the available research findings is perhaps the position adopted by McDonough (1999: 13) who argues that: "The relationship between strategy use and proficiency is very complicated. Issues such as frequency and quality of strategy use do not bear a simple linear relationship to achievement in a second language". Aside from the influence of intervening variables which may conspire against identifying positive correlations between the use of strategies and achievement, much also depends on the mode of instruction and assessment procedures to which the subjects are exposed, as well as research design and the operationalization of the two variables. In fact, all such factors could have affected the results of the study to which we now turn our attention.

\section{Research questions, methodology and analytical procedures}

The main aim of the study reported below was to examine the relationship between the use of grammar learning strategies and attainment in learning English, operationalized as the degree of success in grammar classes and a comprehensive end-of-the-year examination covering all aspects of TL proficiency. To be more precise, the research project sought to provide insights in the following areas: (1) the relationship between the use of GLS, achievement in learning grammar and overall English proficiency, (2) the existence of such a relationship as a function of the level in the BA program, (3) the 
relationship between various categories of GLS and attainment, (4) the differences in GLS use between upper-level and lower-level participants.

The participants were 142 English Departments students, 67 of whom were in the first year of their BA program, 38 in the second and 37 in the third. In the course of the program, the students were expected to attend many practical English classes, with separate segments in pronunciation, grammar, conversation, writing and integrated skills, as well as a number of content classes such as descriptive grammar, linguistics, English and American literature or language teaching methodology. The subjects reported having learnt English for an average of 9.89 years, with substantial variation in this respect, as evidenced by the high values of standard deviation (2.70) and range (17.0). As dictated by the requirements of the program, the students were advanced users of English, representing the B2, C1 or even C2 levels, and they self-rated their English proficiency as 4.02 (3.78 in year 1, 3.92 in year 2 and 4.35 in year 3 ) on a six-point scale, where 1 indicated the lowest and 6 the highest level, with the standard deviation of 0.57 testifying to considerable homogeneity of the responses. As regards their out-ofclass access to English, most of the subjects (128 or 90.14\%) stated that although they had such opportunities, they were mostly limited to the Internet, television and newspapers rather than real-life contacts with TL users. It should also be noted that the participants were convinced of the importance of learning English grammar, giving this subsystem an average ranking of 4.16 on a scale of 1 (lowest) to 6 (highest), and did not vary much in this respect, as is visible from the relatively small value of standard deviation which stood at 0.68. In what seems to be an interesting pattern, the significance attached to learning grammar increased with each successive year (4.10 in year 1, 4.18 in year 2 and 4.20 in year 3 ) and although the differences did not reach statistical significance, it could be hypothesized that the third year students were more likely to appreciate the role of grammar as a tool for attaining clarity and precision. It could also be reasonably assumed that by virtue of their familiarity with various approaches to teaching grammar as a result of completing methodology courses, experience in attending narrowly focused grammar classes as well as the need to prepare for end-of the-year examinations in their own time, the participants in the last year of the program must have developed their own set of grammar learning strategies.

The data used to explore the relationship between GLS use and proficiency included the responses in a questionnaire which the students were requested to complete in their regular classes, the final grades they were accorded in their practical grammar course and the grades they received in an end-of-the year examination in English which determines whether or not they are allowed to enter the next level in the BA program. The survey consisted of two parts, the first of which contained open-ended and closed items intended to provide factual information about the subjects, their views about the importance of learning grammar and their favorite ways of studying it. The second part, which was the main source of data in the research project reported below, drew upon the descriptive scheme proposed by Oxford, Rang Lee and Park (2007) and included Likertscale items representing three groups different grammar learning strategies associated with implicit learning with focus on form, explicit deductive learning and explicit inductive learning. Not being acquainted with the labels of the three categories, the students had to indicate the extent to which a particular statement was true about them on a five-point scale, where 1 meant that it did not describe them at all and 5 that it 
perfectly reflected their thoughts and actions. When it comes to the measures of attainment, the final grades in the grammar course were reflective of the combined scores of a number of tests that the subjects had been required to take during the academic year and took the form of numbers from 2 (lowest) to 5 (highest). The same grading system was employed to evaluate the participants' performance on the examination, the crucial difference lying in the fact that in this case assessment was much more comprehensive and more representative of overall TL proficiency. This is because the examination consisted of three parts in which the students were required to write a paragraph, essay or summary, complete a test focusing on grammar, lexis and reading, and take part in an oral interview where all the components of communicative competence were evaluated.

The analysis of the collected data was mainly quantitative, the only exception being the open-ended question concerning the respondents' favorite ways of learning grammar, in which case it was complemented by qualitative procedures. In the first place, the means and standard deviations were computed for all the questions requiring numerical responses, including the Likert-scale statements representing different GLS, with separate calculations being made for each of the three instructional modes, each of the three levels of the program and the sample as a whole. Subsequently, the means were correlated with the grades the subjects received in the grammar course and the end-ofthe-year examination, but also in this case the results were broken down for each level and strategy category, and the relationships between attainment and the frequency of strategy use in each instructional mode for each year were determined (e.g. in year 1 correlations were established between the grammar course grades, the exam and GLS use associated with implicit learning with focus on form, explicit inductive learning and explicit deductive learning). Lastly, in order to further explore the connection between GLS use and TL proficiency, the students were divided into the upper level and lower level depending on the grades they received in the grammar course and the examination, with the former comprising individuals with a 4, 4.5 or a 5 (49 for the course and 32 for the exam) and the latter consisting of those with a 2, 3 or 3.5 (93 for the course and 110 for the exam). Also here calculations were made separately in the two groups for the three categories representing three modes of instruction. Since in most instances the data were not normally distributed, the statistical significance of the relationship between GLS use and attainment was established by means of Spearman's rank order correlation while the significance of the differences in the application of strategies was established with the help of the Mann-Whitney test.

\section{Results and discussion}

Although detailed analysis of the use of grammar learning strategies as a function of the mode of instruction is beyond the scope of the present paper and can be found in another publication (Pawlak 2009a), it seems warranted to inspect the frequency with which the subjects reported employing the three GLS categories before exploring the relationship between the application of strategic devices and achievement. As illustrated in Table 1, the mean score for overall strategy use stood at 3.49, which indicates a relatively high rate of frequency (Oxford 1990). It was the second year students who reported using the 
GLS most frequently with an average of 3.57 , higher by 0.12 than the means obtained for the first and third year participants (3.45 in both cases), with the differences failing to reach statistical significance. When it comes to the application of the GLS associated with the three instructional modes, the mean frequency was the highest for implicit learning with focus on form (3.59), followed by explicit deductive learning (3.46) and explicit inductive learning (3.42), with the differences between the first category and the remaining two being statistically significant $(z=3.26, p=.0011$ and $z=3.03, p=.0025$, respectively). By and large, such findings were reflected in each of the three groups of students since the reported mean frequency of GLS use was always highest for implicit learning with focus on from, with the caveat that only in year 1 did the differences of 0.28 (implicit vs. inductive) and 0.23 (implicit vs. deductive) prove statistically significant ( $z=3.00, p=.0027$ and $z=2.82, p=.0048$, respectively). A deviation from the general pattern could only be observed in year 2 where the mean for inductive learning slightly exceeded that for deductive learning (3.55 vs. 3.52), but neither this nor any other comparisons between groups yielded statistically significant differences.

Table 1: Average frequencies of grammar learning strategy use as a function of year and instructional mode.

\begin{tabular}{|c|c|c|c|c|}
\hline Type of GLS & $\begin{array}{c}\text { Year I } \\
\text { Mean } \\
\mathbf{( N = 6 7 )}\end{array}$ & $\begin{array}{c}\text { Year II } \\
\text { Mean } \\
(\mathbf{N = 3 8})\end{array}$ & $\begin{array}{c}\text { Year III } \\
\text { Mean } \\
\mathbf{( N = 3 7 )}\end{array}$ & $\begin{array}{c}\text { Total } \\
\text { Mean } \\
\mathbf{( N = 1 4 2})\end{array}$ \\
\hline Implicit learning with focus on form & 3.62 & 3.63 & 3.51 & $\mathbf{3 . 5 9}$ \\
\hline Explicit inductive learning & 3.34 & 3.55 & 3.36 & $\mathbf{3 . 4 2}$ \\
\hline Explicit deductive learning & 3.39 & 3.52 & 3.48 & $\mathbf{3 . 4 6}$ \\
\hline Total & $\mathbf{3 . 4 5}$ & $\mathbf{3 . 5 7}$ & $\mathbf{3 . 4 5}$ & $\mathbf{3 . 4 9}$ \\
\hline
\end{tabular}

On the face of it, such results might be interpreted as quite promising as not only do they indicate that the participants used the GLS included in the survey with a high rate of frequency and in a relatively uniform manner, but also that they manifested awareness of the need to learn and practice grammatical structures in meaning and message conveyance. Still, excessive optimism should be tempered in view of the fact that in response to the question concerning their favorite ways of learning grammar, the subjects listed only a very limited range of quite traditional strategies such as formal practice and only $15 \%$ made references to using the structures taught in spontaneous communication. This indicates that the responses to the Likert-scale items should be treated with circumspection since they may not be reflective of the typical ways in which the subjects go about learning grammar, either because the data collection instrument itself is flawed in some way and produced a distorted picture of reality or the students wanted to paint themselves in a favorable light stipulating that frequent use of GLS may be desirable. These are crucial points that will be revisited later, as they may partly account for the observed relationship between strategy use and attainment, and contribute to better design of similar research projects in the future. 
Table 2: Correlations between grammar learning strategy use and achievement measures (statistically significant results are indicated with an asterisks).

\begin{tabular}{|c|c|c|c|c|}
\hline $\begin{array}{l}\text { Achievement } \\
\text { measure }\end{array}$ & $\begin{array}{c}\text { Overall } \\
\text { GLS use }\end{array}$ & $\begin{array}{c}\text { Implicit learning } \\
\text { with focus on form } \\
\text { GLS }\end{array}$ & $\begin{array}{c}\text { Explicit } \\
\text { inductive } \\
\text { learning GLS }\end{array}$ & $\begin{array}{c}\text { Explicit } \\
\text { deductive } \\
\text { learning GLS }\end{array}$ \\
\hline \multicolumn{5}{|l|}{$\begin{array}{c}\text { Grammar course } \\
\text { grade }\end{array}$} \\
\hline $\begin{array}{l}\text { All levels } \\
\text { combined }\end{array}$ & 0.06 & 0.02 & 0.01 & $0.14^{*}$ \\
\hline Year 1 & 0.13 & 0.09 & 0.08 & $0.22 *$ \\
\hline Year 2 & -0.09 & -0.21 & -0.20 & 0.05 \\
\hline Year 3 & 0.14 & 0.18 & 0.13 & 0.14 \\
\hline \multicolumn{5}{|l|}{$\begin{array}{c}\text { Final } \\
\text { examination } \\
\text { grade }\end{array}$} \\
\hline $\begin{array}{l}\text { All levels } \\
\text { combined }\end{array}$ & -0.07 & -0.04 & -0.07 & -0.03 \\
\hline Year 1 & 0.01 & 0.00 & 0.01 & 0.07 \\
\hline Year 2 & -0.17 & -0.05 & -0.18 & -0.17 \\
\hline Year 3 & -0.01 & 0.01 & -0.03 & -0.02 \\
\hline
\end{tabular}

Table 2 above presents the correlations between the two achievement measures selected for the purpose of the study, namely the grammar course grades and final exam results, and the use of different types of grammar learning strategies at the three levels of the BA program. What comes as a surprise taking into account the findings of much previous research and the confident claims of specialists quoted above, the relationship between the use of GLS and attainment proved to be extremely weak and mostly statistically insignificant, and in quite a few cases negative correlations were indentified. In the first place, no meaningful correlation was found between the application of grammar learning strategies and either achievement measure, irrespective of whether the participants were the first, second or third year students. In fact, not only do the results indicate that overall strategy use accounted for less than $1 \%$ of the variance in the grammar course grade for all the participants $\left(r_{s}=0.06\right)$, but also that the relationship between GLS use and the examination grades was negative $\left(r_{s}=-0.07\right)$. Although the latter correlation did not reach statistical significance and it was extremely weak, such a finding is disconcerting because it indicates that more frequent application of GLS is likely to be accompanied by lower examination scores, a tendency that was most pronounced in year 
$2\left(r_{s}=-0.07\right)$. By contrast, the highest positive correlations were revealed in year 1 and 3 for the participants' grammar course grades $\left(r_{s}=0.13\right.$ and $\left.r_{s}=0.14\right)$, but they were statistically insignificant and so weak that they explained merely about $2 \%$ of the variability in attainment.

As regards the link between the three different categories of GLS and achievement, the strongest positive relationship was found between the use of strategies associated with explicit deductive learning and grammar course grades $\left(r_{s}=0.14\right)$, and it was in fact one of two cases in which the required level statistical significance was reached $(p=$ 0.0445). This finding may be may be indicative of the predominant types of instruction and assessment in the grammar classes the students attended, an interpretation which is consistent with the results of some previous research (Pawlak 2008a). Still, it should be emphasized that, statistically significant or not, also in this case the correlation was extremely weak since it explained just around $2 \%$ of the variance in achievement. The remaining two GLS categories in practice unrelated to the grammar course grades, with the correlation coefficient oscillating around 0.00 whereas a reverse relationship between all the three GLS types and the final examination grades was found, which, however, was very weak (correlation coefficients in the range of 0.03 and 0.07 ) and did not approach significance. Finally, comments are in order on the interaction between different types of grammar learning strategies and student attainment at different levels of the program. When we examine the data included in Table 2, it turns out that the highest positive relationship held between GLS used in explicit deductive learning and grammar course grades in year $1\left(r_{s}=0.22\right)$, with Spearman's rho satisfying the necessary level of significance $(p=0.0391)$. This result, coupled with a positive, albeit not statistically significant correlation in year $3\left(r_{s}=0.14\right)$ might provide further evidence for the preferred instructional approaches and types of evaluation in grammarbased classes. It should be kept in mind, though, that even in the case of this highest positive correlation, GLS use associated with deductive learning accounted for just around $5 \%$ of the variance in course grades, which speaks to the overall weak relationships between strategy use and achievement. Other positive relationships with grammar course grades that are worth highlighting here are those involving GLS related to implicit learning with focus on form and explicit inductive learning in year 3, which explained $3.6 \%\left(r_{s}=0.18\right)$ and $1.7 \%\left(r_{s}=0.13\right)$ of the variance in attainment, respectively, but failed to reach statistical significance $(p=0.1419)$. All the remaining positive correlations were even weaker while those which were close to approaching significant levels pointed to a negative relationship. In accordance with the trend detected for overall strategy use, such cases could be observed with the exam scores where the correlation coefficients for GLS associated with inductive and deductive learning in year 2 equaled -0.18 and -0.17 . Although these numbers were not statistically significant, it does come as a surprise that those second year students who reported frequent use of GLS in the two categories tended to receive lower grades on the exam, a finding that can perhaps be accounted for by the nature of this achievement measure which covered the mastery of various skills and language subsystems. 
Table 3: Grammar strategy use by upper-level and lower-level students (no statistically significant differences).

\begin{tabular}{|c|c|c|c|c|c|c|c|c|}
\hline \multirow{3}{*}{$\begin{array}{l}\text { Achievement } \\
\text { measure }\end{array}$} & \multicolumn{8}{|c|}{ GLS use mean $(N=142)$} \\
\hline & \multicolumn{4}{|c|}{$\begin{array}{c}\text { Upper-level students } \\
\text { ( } N=49 \text { for course and } N=32 \text { for exam) }\end{array}$} & \multicolumn{4}{|c|}{$\begin{array}{l}\text { Lower-level students } \\
\text { ( } N=93 \text { for course and } N=110 \text { for exam) }\end{array}$} \\
\hline & Total & $\begin{array}{c}\text { Implicit } \\
\text { learning with } \\
\text { focus on form }\end{array}$ & $\begin{array}{l}\text { Explicit } \\
\text { inductive } \\
\text { learning }\end{array}$ & $\begin{array}{c}\text { Explicit } \\
\text { deductive } \\
\text { learning }\end{array}$ & Total & $\begin{array}{c}\text { Implicit } \\
\text { learning with } \\
\text { focus on form }\end{array}$ & $\begin{array}{c}\text { Explicit } \\
\text { inductive } \\
\text { learning }\end{array}$ & $\begin{array}{c}\text { Explicit } \\
\text { deductive } \\
\text { learning }\end{array}$ \\
\hline $\begin{array}{l}\text { Course grade } \\
\text { Exam grade }\end{array}$ & \begin{tabular}{|l|}
3.49 \\
3.41 \\
\end{tabular} & $\begin{array}{l}3.58 \\
3.49\end{array}$ & $\begin{array}{l}3.42 \\
3.37\end{array}$ & $\begin{array}{l}3.45 \\
3.36\end{array}$ & \begin{tabular}{|l|}
3.43 \\
3.42 \\
\end{tabular} & $\begin{array}{l}3.58 \\
3.60\end{array}$ & $\begin{array}{l}3.35 \\
3.38\end{array}$ & $\begin{array}{l}3.36 \\
3.29\end{array}$ \\
\hline
\end{tabular}

The last research question addressed the issue of the use of grammar learning strategies by the upper-level and lower-level participants, with comparisons being made for all the GLS as well as the strategic devices falling into the categories of implicit learning with focus on form, explicit inductive learning and explicit deductive learning. As demonstrated in Table 3, the two groups of participants did not differ in any substantial way in their frequency of use of GLS, either overall or with respect to specific types of behaviors, irrespective of whether the level of proficiency was established on the basis of the grades received in the grammar course or in the final exam. Still, even tough the disparities in the means were indeed minute, ranging from 0.00 to 0.11 and never reaching statistical significance, some interesting patterns could be observed in the data. For one thing, it is clear that more frequent GLS use, both overall and in two out of the three categories, was reported by the subjects who manifested superior performance in the grammar course. While the overall difference of 0.04 is almost negligible and the disparities of 0.07 and 0.09 in the use of GLS associated with inductive and deductive learning are very small, they indicate that strategy use may be in some way related to success in a course narrowly focused on studying and practicing grammatical structures, often in quite traditional ways. A slightly different picture emerged when the subjects were divided into the upper and lower levels on the basis of their performance in the final exam since in this case it was the less successful students who reported a marginally higher GLS, both overall and in two of the three categories. The most interesting observation here seems to be the difference in their favor in the application of strategies representing implicit learning, which amounted to 0.11 and was the only one nearing statistical significance $(z=-1.39 ; p=01560)$. It should also be noted that GLS related to explicit deductive learning were still applied more often by students who did better on the exam, which, together with the findings described above, might indicate that they are somewhat more predictive of attainment than the other two categories.

A pertinent question to ask at this point is why the investigation failed to reveal stronger relationships between the use of GLS and attainment as well as why so many negative, albeit weak, correlations were identified, especially in the case of the final examination grades. One viable explanation is that the data collection instrument might not have been a fully adequate tool to provide valid information about the application of grammar learning strategies, which can be attributed to its shortcomings mentioned earlier in this paper. Particularly damaging could have been insufficient emphasis on strategic devices involved in practicing grammatical structures, especially those 
involving formal practice, in view of the fact that it was such GLS that the students most often included in their responses to the open-ended question about their favorite ways of learning grammar. Another problem could have been the failure to include a greater number of metacognitive and memory strategies that learners are known to employ to enhance their mastery of any skills or subsystem (e.g. grouping, association, setting goals) as well as the fact that that the taxonomy comprised many cognitive devices that might have been unfamiliar to many respondents (input-enhancement, garden-path technique, dictogloss, etc.). The latter problem could have accounted for the astonishingly high use of GLS related to implicit learning with focus on form which failed to be reflected in descriptive responses, as the participants could have decided to play it safe and indicated frequent use of behaviors regarded as beneficial. Judging from the average use of specific types of strategies by upper- and lower-level students, a propensity of this kind was particularly evident among the latter, which might have blurred the relationship between GLS use and attainment.

The predominance of weak relationships and the occurrence of a considerable number of negative correlations may also be connected with the choice of the measures of achievement employed in the present study as well as their compatibility with the types of instruction and assessment that the students received. As regards the final grades in the grammar course, they were accorded on the basis of test scores the students had accumulated in the course of the academic year, but in some cases they were also influenced by retakes as well as such factors as in-class participation or attendance, with the effect that they may not have always reflected accurately the true abilities of the subjects. In addition, since both instruction and assessment were mainly based on the application of explicit, declarative knowledge in what Ellis (1997) calls textmanipulation activities (completion, translation, etc.), frequent use of GLS related to implicit learning or induction, even if it did take place in reality, may not have translated into better grades in the course. On the other hand, however, it was for grammar course grades that the strongest positive correlations between GLS use and attainment were identified, including those which were statistically significant, which points to a degree of compatibility between teaching, learning and assessment. This applied in particular to GLS involved in explicit deductive learning, which, as noted above, provides further evidence for the weight given to traditional instructional approaches and insufficient concern with using the structures taught in communication. The negative correlations between GLS use and performance on the final exam, in turn, could have resulted from the fact that grammar is just one of the components of communicative competence evaluated on this achievement measure. Besides, the mastery of grammar is once again mainly tested through translation, transformation or multiple choice tasks, and although mastery of this subsystem is required when constructing a written text or taking part in an interview, it is students who ultimately decide what structures to use and they can always resort to avoidance. Equally importantly, a high score on a grammar test does not guarantee passing the examination, when the student fails to reach the threshold performance level in the written and oral components, or, conversely, a low score may to some extent be compensated for by superior performance on its other parts, which means that in at least some cases, the aggregate grade may fail to give justice real command of grammar. Although these considerations partly explain the weak correlations between GLS use and examination results, the real conundrum are the negative relationships 
revealed in some cases. It could perhaps be speculated that the final outcome of this comprehensive and multifaceted exam precludes the existence of strong correlations with strategies involved in the learning of just one subsystem since many diverse variables are involved, the interaction of which is bound to be exceedingly complex. Thus, in subsequent studies of this kind, it might be advisable to seek a relationship between GLS use and the scores on different subcomponents of this achievement measure in the hope of detecting more meaningful relationships.

\section{Conclusions and implications}

As can be seen from the foregoing discussion, the present study has failed to find evidence for the existence of a strong positive relationship between the use of grammar learning strategies and attainment, operationalized as the grades received in a grammar course and performance on the final examination, which stands in contrast to much previous research focused on more general strategic devices. In fact, all the positive correlations were rather weak irrespective of the level in the BA program or strategy type, including those that were statistically significant, and, particularly in the case of the final exam grades, a number of negative relationships could be observed. The positive correlations were mainly found for the grammar course grades, but only GLS associated with explicit deductive learning proved to be meaningfully related to this achievement measure. While this relationship was not strong and accounted for a maximum of $5 \%$ of the variance in the grades the participants received, it seems to speak volumes about the nature of grammar instruction as well as the assessment of the students' progress in the BA program, indicating that premium is placed on accurate application of rules in exercises rather than applying them in genuine communication. Finally, no statistically significant differences were found in GLS use reported by upper- and lower-level students, although those who received higher grades in the grammar course did employ such devices slightly more often.

Discouraging as these findings may seem, it should be emphasized that this was only a preliminary study of the relationship between GLS use and language achievement and, thus, it would be premature to draw definitive conclusions on its basis. As was pointed out above, the results could have been affected by a number of factors connected with the weaknesses of the data collection instrument and the nature of the achievement measures, and it is possible that improvement in these areas might lead to identifying stronger positive correlations in future research. The value of the study also lies in the fact that the search for a relationship between the employment of strategies for learning grammar and target language achievement provided valuable insights into the nature of instruction and assessment procedures. This is because, the positive, even if relatively weak, relationship between GLS associated with explicit deductive learning and the fact that such strategies were applied more often by more successful students, testify to an emphasis on formal practice in grammar courses and the application of rules in controlled activities on achievement tests and the final examinations. While such a tendency is understandable given the requirement that students in foreign languages departments attain superior levels of proficiency, there is clearly a need for more focus on the application of the consciously known structures in real communication, since only 
then can we ensure the development of implicit alongside explicit knowledge as well as its more consistent, accurate or appropriate use (Pawlak 2006). A closely related issue is acquainting students with a whole gamut of GLS, especially those involved in implicit learning with focus on form, as this will provide an additional stimulus for the use of points of grammar to convey genuine messages and enhance the chances of specific features being attended to, noticed and incorporated into the developing L2 system. Such measures are likely to sensitize students to the importance of the communicative dimension of grammar, especially if they are accompanied by changes in assessment procedures so that they necessitate more spontaneous use of specific structures.

The results of the study also unambiguously demonstrate that there is an urgent need for more research in the area of the actions and thoughts learners undertake in studying and practicing grammar. As the present author has stressed elsewhere (Pawlak 2008a, 2009a), the most pressing issue is the development of a comprehensive classification of GLS as well as the construction on its basis of a valid and reliable data collection tool, which indicates that empirical investigations seeking to identify and describe strategic behaviors should be the top priority. Obviously, this does not mean that researchers should not seek to appraise the value of particular GLS, determine the relationship between GLS use and achievement or examine the diverse factors influencing the application of such devices with the help of the instruments currently at their disposal. Although the findings of such preliminary research will necessarily be fragmentary, mixed and inconclusive, they are likely to provide invaluable insights which can be drawn upon when proposing and refining GLS taxonomies or research instruments. Indeed, the study reported above is a good case in point since, even though it failed to detect a strong relationship between strategy use and attainment, it did point to the ways in which the process of data collection can be improved and achievement should be operationalized, not to mention the pedagogical recommendations it permitted. This goes to show that it perhaps makes more sense to grope somewhat in the dark in the hope of uncovering enough pieces of the puzzle to reveal a more or less complete picture of GLS than to sit on our hands relying on theoretical models that fail to give justice to the complexity of activities students fall back upon to make the process of learning grammar more effective, self-direct and enjoyable.

\section{References}

Anderson, N. 2005. L2 learning strategies. In Hinkel, E. (ed.). 2005. 757-771.

Bade, M. 2008. Grammar and good language learners. In Griffiths, C. (ed.). 2008b. 174184.

Bialystok, E. 1981. The role of conscious strategies in second language proficiency. Modern Language Journal 65. 24-35.

Bremner, S. 1999. Language learning strategies and language proficiency: Investigating the relationship in Hong Kong. Canadian Modern Language Review 55. 490-514.

Carter, R. and Nunan, D. (eds). 2001. The Cambridge guide to teaching English to speakers of other languages. Cambridge: Cambridge University Press.

Chamot, A. U. 2004. Issues in language learning strategy research and teaching. Electronic Journal of Foreign Language Teaching 1. 12-25. 
Cohen, A. D. and Macaro, E. (eds). 2007. Language learner strategies. Oxford: Oxford University Press.

DeKeyser, R. 2003. Implicit and explicit learning. In Doughty, C. J. and Long, M. H. (eds). 2003. 313-348.

Dörnyei, Z. 2005. The psychology of the language learner: Individual differences in second language acquisition. Mahwah, NJ: Erlbaum.

Doughty, C. J. 2003. Instructed SLA. In Doughty, C. J. and Long, M. H. (eds). 2003. 256-310.

Doughty, C. J. and Long, M. H. (eds). 2003. The handbook of second language acquisition. Oxford.: Blackwell.

Dreyer, C. and Oxford, R. L. 1996. Learning strategies and other predictors of ESL proficiency among Afrikaans speakers in South Africa. In Oxford, R. L. (ed.). 2001b. 61-74.

Droździał-Szelest, K. 1997. Language learning strategies in the process of acquiring a foreign language. Poznań: Motivex.

Erhman, M., Leaver, B. and Oxford, R. L. 2003. A brief overview of individual differences in language learning. System 31. 313-330.

Ellis, R. 1994. The study of second language acquisition (first edition). Oxford: Oxford University Press.

Ellis, R. 1997. SLA research and language teaching. Oxford: Oxford University Press.

Ellis, R. 2006. Current issues in the teaching of grammar: An SLA perspective. TESOL Quarterly 40. 83-107.

Ellis, R. 2008. The study of second language acquisition (second edition). Oxford: Oxford University Press.

Fortune, A. 1992. Self-study grammar practice: Learners' views and preferences. ELT Journal 46. 160-171.

Green, J. M. and Oxford, R. L. 1995. A closer look at learning strategies, L2 proficiency and gender. TESOL Quarterly 29. 261-297.

Grenfell, M. and Macaro, E. 2007. Claims and critiques. In Cohen, A. D. and Macaro, E. (eds). 2007. 9-28.

Griffiths, C. 2008a. Strategies and good language learners. In Griffiths, C. (ed.). 2008b. 83-98

Griffiths, C. 2008b. (ed.). Lessons form good language learners. Cambridge: Cambridge University Press.

Hinkel, E. (ed.). 2005. Handbook of research in second language teaching and learning. Mahwah, NJ: Lawrence Erlbaum Associates.

Karmiloff-Smith, A. 1979. A functional approach to child language. Cambridge: Cambridge University Press.

Larsen-Freeman, D. 2003. Teaching language: From grammar to grammaring. Toronto: Thomson and Heinle.

Macaro, E. 2001. Learning strategies in foreign and second language classrooms. London: Continuum.

Macaro, E. 2006. Strategies for language learning and for language use: Revising the theoretical framework. Modern Language Journal 90. 320-337. 
Magogwe, J. M. and Oliver, R. 2007. The relationship between language learning strategies, proficiency, age and self-efficacy beliefs: A study of language learners in Botswana. System 35. 338-352.

McDonough, S. 1999. Learner strategies. Language Teaching 32. 1-18.

Mullins, P. Y. 1992. Successful English language learning strategies of students enrolled at the Faculty of Arts, Chulalongkorn University, Bangkok, Thailand. Unpublished $\mathrm{PhD}$ dissertation, International University, San Diego, CA.

Mystkowska-Wiertelak, A. 2008a. The use of grammar learning strategies among secondary school students. In Pawlak, M. (ed.). 2008b. 139-148.

Mystkowska-Wiertelak, A. 2008b. Rozwijanie autonomii przy użyciu Europejskiego portfolio językowego a podnoszenie poziomu poprawności gramatycznej [Developing autonomy by means of the European Language Portfolio and increasing grammatical accuracy. In Pawlak, M. (ed.). 2008c. 197-206.

Naiman, N., Fröhlich, M., Stern, H. H. and Todesco, A. 1996 (1978). The good language learner. Clevedon: Multilingual Matters.

Nisbet, D. L., Tindall, E. R. and Arroyo, A. A. 2005. Language learning strategies and English proficiency of Chinese university students. Foreign Language Annals 38. 100-107.

Oliphant, K. 1997. Acquisition of grammatical gender in Italian as a foreign language. (Net Work \#7). Honolulu: University of Hawaii (http://nflrc.hawaii.edu/NetWorks/NW07/NW07.pdf).

O'Malley, J. M. and Chamot, A. U. 1990. Learning strategies in second language acquisition. Cambridge: Cambridge University Press.

Osanai, D. 2000. Differences in language learning strategies between male and female, and also between Asian and Latino ESL students. Unpublished $\mathrm{PhD}$ dissertation, University of Tennessee, Knoxville, TN.

Oxford, R. L. 1990. Language learning strategies: What every teacher should know. Boston, M.A.: Heinle.

Oxford, R. L. 2001. Language learning strategies. In Carter, R. and Nunan, D. (eds). 2001. 166-172.

Oxford, R. L. (ed.). 2001b. Language learning strategies around the world: Crosscultural perspectives. Manoa: University of Hawaii Press.

Oxford, R. L. and Ehrman, M. 1995. Adults' language learning strategies in an intensive foreign language program in the United States. System 23. 359-386.

Oxford. R. L., Rang Lee, K. and Park, G. 2007. L2 grammar strategies: the Second Cinderella and beyond. In Cohen, A. D. and Macaro, E. (eds). 2007. 117-139.

Park, G. P. 1994. Language learning strategies: Why do adults need them?. Manuscript, University of Texas, Austin, TX.

Park, G. P. 1997. Language learning strategies and English proficiency in Korean university students. Foreign Language Annals 30. 211-221.

Pawlak, M. 2006. The place of form-focused instruction in the foreign language classroom. Kalisz-Poznań: Adam Mickiewicz University Press.

Pawlak, M. 2008a. Advanced learners' use of strategies for learning grammar: A diary study. In Pawlak, M. (ed.). 2008b. 109-125.

Pawlak, M. (ed.). 2008b. Investigating English language learning and teaching. Poznań - Kalisz: Adam Mickiewicz University Press. 
Pawlak, M. (ed.). 2008c. Autonomia w nauce języka obcego - co osiagnęliśmy i dokad zmierzamy [Autonomy in language learning: Achievement and prospects for the future]. Poznań - Kalisz - Konin: Adam Mickiewicz University Press and State School of Higher Professional Education in Konin Press.

Pawlak, M. 2009a. Instructional mode and the use of grammar learning strategies. In Pawlak, M. (ed.). 2009.

Pawlak, M. (ed.). 2009b. New perspectives on individual differences in language learning and teaching (Special issues of Studies in Pedagogy and Fine Arts Vol. VIII). Poznań - Kalisz: Adam Mickiewicz University Press.

Philips, V. 1991. A look at learner strategy use and ESL proficiency. The CATESOL Journal 4. 57-67.

Politzer, R. L. and McGroarty, M. 1985. An exploratory study of learning behaviors and their relationship to gains in linguistic and communicative competence. TESOL Quarterly 19. 103-123.

Reiss, M. A. The good language learner: Another look. Canadian Modern Language Review 41. 511-23.

Rubin, J. 1975. What the 'Good Language Learner' can teach us. TESOL Quarterly 9. 41-51.

Sheorey. R. 1999. An examination of language learning strategy use in the setting of an indigenized variety of English. System 27. 173-190.

Stern, H. H. 1975. What can we learn from the good language learner? Canadian Modern Language Review 31. 304-318.

Stevens, F. 1984. Strategies for second language acquisition. Montreal: Eden Press.

Takeuchi, O. 1993. Language learning strategies and their relationship to achievement in English as a foreign language. Language Laboratory 30. 17-34.

Takeuchi, O., Griffiths, C. and Coyle, D. 2007. Applying strategies to contexts: The role of individual, situational, and group differences. In Cohen, A. D. and Macaro, E. (eds). 2007. 69-92.

Tilfarlioğlu, Y. 2005. An analysis of the relationship between the use of grammar learning strategies and student achievement at English preparatory classes. Journal of Language and Linguistic Studies 1. 155-169.

Wharton. G. 2000. Language learning strategy use of bilingual foreign language learners in Singapore. Language Learning 50. 203-243. 